\title{
Alcohol Influence in Violent Deaths
}

\author{
Manoel E S Modelli ${ }^{1^{*}}$ and Stephane Mota Lourenco ${ }^{2}$ \\ ${ }^{1}$ Institute of Legal Medicine of the DF, Federal District Civil Police, Brasilia, Brazil \\ ${ }^{2}$ Unified Teaching Center of Brasilia - Uniceub, Brasilia, Brazil
}

Corresponding author: Manoel E S Modelli, Institute of Legal Medicine of the DF, Federal District Civil Police, Brasilia, Distrito Federal 70273-040, Brazil, Tel: 55 (61) 99823186; E-mail: manoelmodelli@gmail.com

Received date: May 22, 2016, Accepted date: Jun 03, 2016, Published date: Jun 07, 2016

Copyright: (c) 2016 Manoel ESM, et al. This is an open-access article distributed under the terms of the Creative Commons Attribution License, which permits unrestricted use, distribution, and reproduction in any medium, provided the original author and source are credited.

\begin{abstract}
Alcohol is a psychoactive drug, a central nervous system depressant, which is disinhibitory and causes euphoria. It is the most consumed depressant substance in the world. Its medico legal importance is due to association with changes in higher brain functions, blocking them and encouraging violent behavior directly related to crimes and accidents. The influence of alcohol on the cause of death is the primary factor in a substantial number of violent deaths. The IML-DF analyzes all violent deaths in the Federal District, which in 2014 owned a population of 2,852,000 inhabitants. The Federal District comprises a central region (Pilot Plan) and several satellite towns. In 2014 , necropsy of 1,845 deceased people was due to violent deaths. Among them, 446 had positive blood alcohol and were analyzed in this study. The others had negative or alcohol was not measured due to the time elapsed between fact and death. Among the 1,845 examined deaths, traffic accidents accounted for 782 cases and homicides by firearm and white guns (knives) for 792 deaths. Among the 446 cases examined, the leading cause of death, with positive results for alcohol, was murder (37\%), followed by traffic accidents (31\%). The blood concentration of alcohol ranged from 0.01 to $10.4 \mathrm{~g} / \mathrm{l}$, an average of $1.74 \pm 1.2 \mathrm{~g} / \mathrm{l}$. The average age of the cases was 35 years; and in cases of murder, the most frequent age group was between 18-29 years; and 30-39 years for traffic accidents. The results show a significant association between alcohol consumption and violent deaths.
\end{abstract}

Keywords: Psychoactive; Alcohol; Depressant; Necropsies; Homicide

\section{Introduction}

Alcohol is a legal drug that causes dependence. It is absorbed in its original form, by simple passive diffusion between concentration gradients. It is absorbed almost all by the duodenum and reaches organs with rich blood supply faster, such as brain and lungs [1]. In the brain, it affects the sensory, perceptual, cognitive and motor skills, including muscle control and the balance of the body. Higher brain functions are those that are first blocked by alcohol, making the person less humane. In the most dangerous phase of intoxication, the person has a state of euphoria, sense of well-being, with a tendency to overestimate their own capabilities. She has stereoscopic vision impaired and narrowing of the visual field. In addition, it causes an increase in reaction time and decreases the reflex response and can lead to aggressive states, frustration and depression [2].

When the intake begins, the alcohol has a stimulating effect and can lead to loss of inhibition and increased sociability. With higher levels, loss of judgment, cognitive processes and coordination will occur [3]. Neurological disorders related to alcohol are the devastating part of alcoholism complications. The early symptoms of poisoning appear to result from the preferential polysynaptic involvement of neuronal pathways in the reticular formation of the brainstem, cerebral cortex and cerebellum (above $25 \mathrm{mg} / \mathrm{dl}$ ). A concentration above $100 \mathrm{mg} / \mathrm{dl}$ causes vestibular cerebellar disorders, such as nystagmus, diplopia, dysarthria and ataxia. Autonomic involvement may produce hypotension or hypothermia; and mild confusion can lead to stupor and coma. Ethanol potentiates the inhibition of cerebral cortical neurons activated by GABA [4].
In 1907, an editorial in the Lancet highlighted the relationship between alcohol and traffic accidents. Since then, numerous studies have shown the importance of this relationship [5]. Glucksman [6] reported that alcohol had become the main cause of accidents, injuries and fatalities, contributing to injuries in 2,500 and 1,500 deaths per year in the UK. Numerous studies in fatal victims have shown that $25 \%$ to $50 \%$ had alcohol levels above the legal limit levels. The highest risk group is the young males. Women are less than $5 \%$ of drunk drivers.

Alcohol consumption has been implicated to be the cause in nearly 1.8 million deaths worldwide, with $3.2 \%$ of the total deaths and $2.5 \%$ of the total years of life lost. Deaths are only the tip of the iceberg. For each reported death, it is estimated that 30-50 are hospitalized and 50-100 received care in emergencies [7]. In addition to the deaths related to traffic accidents, alcohol has significant contributions in other types of violent deaths. In a COX study, the incidence of alcohol positive in homicides was $39 \%$ and $32 \%$ in suicides. The incidence of positive blood alcohol levels in natural deaths was only 7\% [8].

Since the beginning of the 80 s, external causes are the second cause of death in Brazil. The mortality rate was $69.7 / 100,000$, which was higher for men. Murders were the leading cause of death $38.8 \%$ of total). External causes have become a significant burden for the people around the world and reducing its morbidity and mortality is one of the main challenges for those responsible for public health policies. Several prevention strategies have been proved effective, as the use of seat belts, stricter traffic laws and educational campaigns about alcohol consumption [9].

To get an idea of the scale of the problem in 1990, about 1.851 million people died due to violence in the world $(35.3 / 100,000)$; this means that 5,000 people die every day due to violence. There were approximately 786,000 suicides $(3.4 / 100,000$ in South Africa and 
Page 2 of 6

$30.4 / 100,000$ in China) and 563,000 homicides (1.1/100,000 in developed countries and 44.8/100,000 in Africa) [10].

The objective of the study was to relate the alcohol to the occurrence of violent deaths in the Federal District, through the analysis of blood alcohol levels of the dead bodies examined in the Institute of Forensic Medicine of the DF, Brazil.

\section{Material and Methods}

The Institute of Forensic Medicine of Brasilia, Federal District is responsible for the analysis of all violent deaths in the Federal District. In 2014, there were 1,845 medico-legal autopsies. Victims with over 24 hours of death or coming from hospitals, after surgery or prolonged hospitalization, severely mutilated or decomposing bodies and burn victims were excluded. Blood samples were collected from all other victims of violent death. All tests were analyzed by the Institute of Laboratory by gas chromatography. In addition to collecting blood for ethanol dosage, the following data were recorded: age, sex, and day of the week, time of day, legal cause of death and mechanism of death. The data were put into an Excel spreadsheet for analysis. The retrospective study was performed in cases of violent deaths and blood alcohol concentration, which totaled 446 victims. The study was approved by the Ethics Committee of the IML-DF.

\section{Results}

The 446 cases examined constitute $30 \%$ of all deaths from external causes, examined in the IML-DF, during the year 2014. The overall average blood alcohol was $1.74 \pm 1.2 \mathrm{~g} / \mathrm{l}$, ranging from $0.01 \%$ to $10.41 \%$. Most cases were male, 408 (91\%), whose average blood alcohol was $1.76 \pm 1.2 \mathrm{~g} / \mathrm{l}$. In females (9\%), the overall average blood alcohol was $1.53 \pm 1 \mathrm{~g} / \mathrm{l}$. The leading cause of death were homicide by firearm (37\%), traffic accidents (31\%), murder with knives (13\%), homicide by physical aggression $(0.3 \%)$, suicide $(0.8 \%)$ and drowning $(0.2 \%)$. The average age of all bodies examined was $35.09 \pm 11.07$ years $(34 \pm 9.44$ years for females and $35.19 \pm 11.21$ for males). Considering the types of accidents, the average age in homicides by firearm was $30.85 \pm 9.38$ years; in the murders with knives was $33.29 \pm 9.49$ years; in homicides by physical aggression was of $38.14 \pm 10.14$; in traffic accidents, the average age was $37.87 \pm 11.09$ years (Table 1 ).

\begin{tabular}{|l|l|l|l|l|}
\hline $\begin{array}{l}\text { Cause/circumstances of } \\
\text { death }\end{array}$ & $\begin{array}{l}\text { Total } \\
\text { cases }\end{array}$ & $\begin{array}{l}\text { Average } \\
\text { age } \\
\text { (years) }\end{array}$ & $\begin{array}{l}\text { Age } \\
\text { group } \\
\text { (years) }\end{array}$ & $\begin{array}{l}\text { Overall average } \\
\text { blood } \\
\text { concentration } \\
\text { (g/l) }\end{array}$ \\
\hline Traffic accidents & 137 & 37.8 & $30-39$ & 2,03 \\
\hline Homicide by firearm & 163 & 30.8 & $18-29$ & 1,29 \\
\hline Murder by weapon & 59 & 33.29 & $30-39$ & 1,98 \\
\hline $\begin{array}{l}\text { Murder by physical } \\
\text { agression }\end{array}$ & 14 & 38.1 & $30-39$ & 2,53 \\
\hline Suicides & 39 & 46 & $30-39$ & Hanging:1,41 \\
\cline { 5 - 6 } & 10 & 29 & $18-29$ & Fall height: 1,28 \\
\hline Drownings & & & & Firearm: 2,96 \\
\hline
\end{tabular}

Table 1: Causes of death, age and alcohol.
The two most frequent causes of deaths were homicides by firearms and traffic accidents. Among the 163 cases of homicide by firearm, 93.2\% were male and the causes of their deaths were hypovolemic shock, polytrauma and traumatic brain injury. Among the 137 cases of traffic accidents, $84 \%$ were male and the main causes of deaths were multiple trauma, head trauma and hypovolemic shock.

The distribution of blood alcohol levels and the number of cases are shown in Figure 1. In Figure 2 are shown the distribution of alcohol in traffic accidents and homicides by firearm. In Figure 3 are shown the distribution of alcohol according to age group.

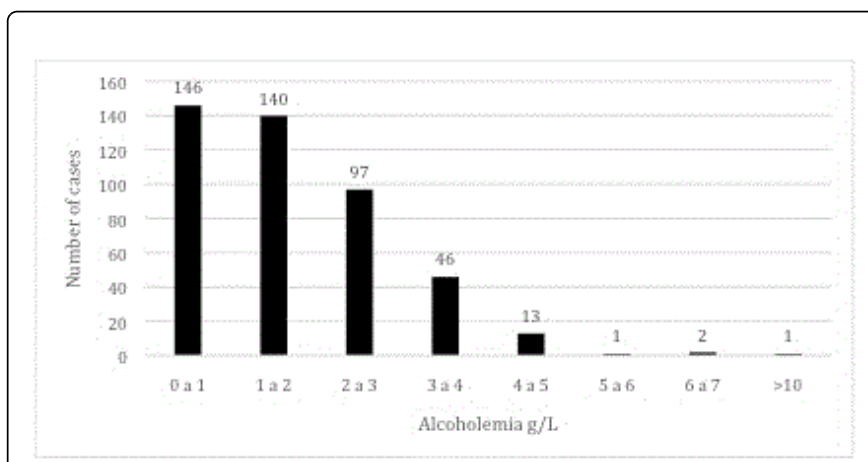

Figure 1: Ranges of alcohol and number of cases.

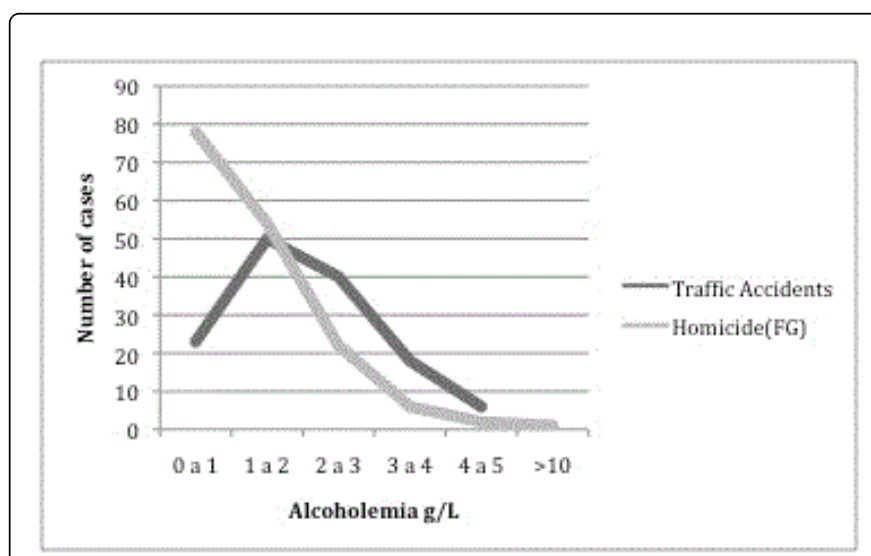

Figure 2: Distribution of alcohol in traffic accidents and homicides by fire arm.

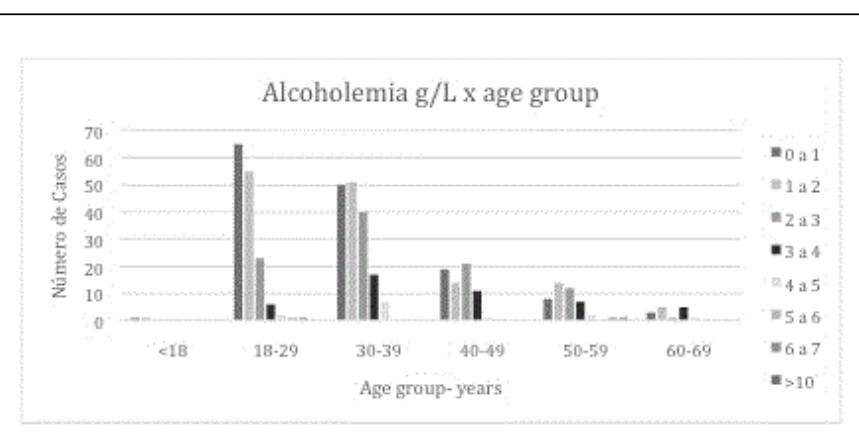

Figure 3: Distribution of alcohol according to age group. 
Page 3 of 6

The violent deaths occurred more during the weekends: Sunday (26.4\%), Saturday (17,2\%), Monday (12,7\%) and Friday (12,5\%) and from $19 \mathrm{pm}$ to $7 \mathrm{am}$ hours. The average blood alcohol content was 1.74 $\pm 1.22 \mathrm{~g} / \mathrm{l}$ in women and $1.76 \mathrm{~g} / \mathrm{l}$ in males, ranging from $0.01 \mathrm{~g} / \mathrm{l}$ to 10.4 g/l (Figures 4 and 5).

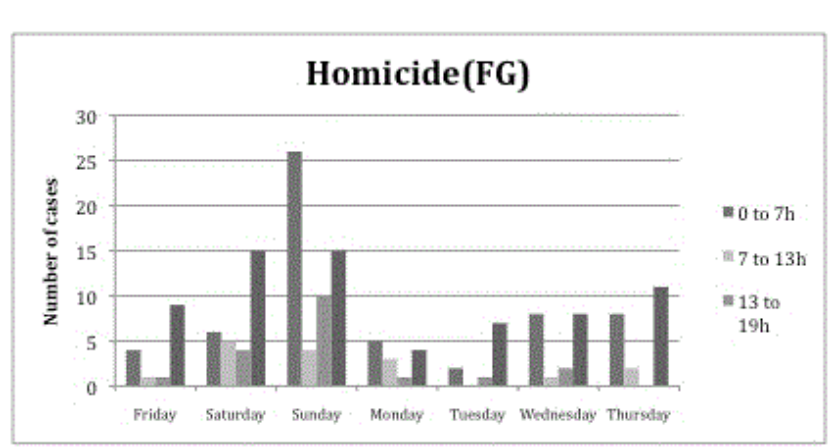

Figure 4: Distribution of cases of murder in relation to the days of the week.

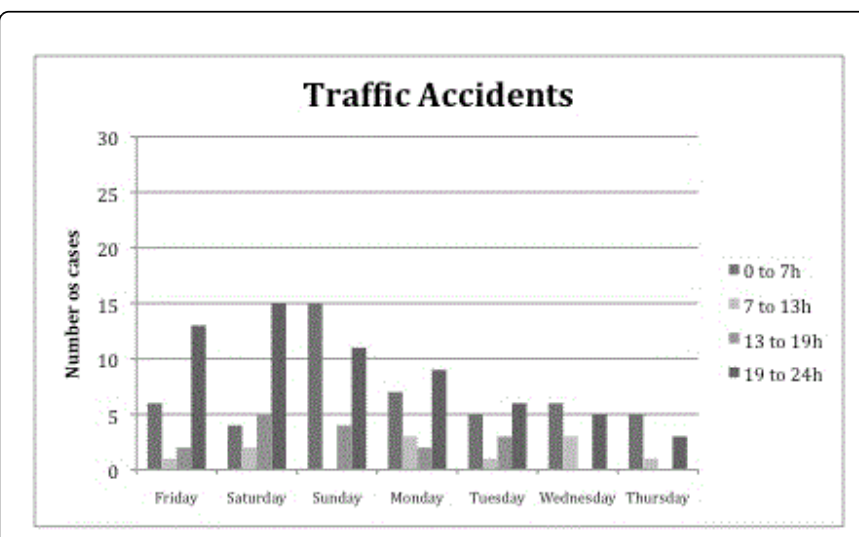

Figure 5: Distribution of cases of traffic accidents and days of the week.

Considering the juridical causes in traffic accidents, the average blood alcohol content $(\mathrm{BAC})$ was $2.03 \pm 1.03 \mathrm{~g} / \mathrm{l}$; in homicides by firearm was $1.29 \mathrm{~g} / \mathrm{l} \pm 1.19 \mathrm{~g} / \mathrm{l}$; in murders with knives was $1.98 \pm 1.08$ $\mathrm{g} / \mathrm{l}$; in homicides by physical aggression was $2.53 \mathrm{~g} / \mathrm{l}$. In suicides was $2.96 \mathrm{~g} / \mathrm{l}$, whereas in the case of hanging using a firearm the BAC was $1.41 \pm 0.98 \mathrm{~g} / \mathrm{l}$ and in case of hanging by falling the BAC was $1.28 \pm$ $0.76 \mathrm{~g} / \mathrm{l}$.

\section{Discussion}

It is well established that the consumption of alcohol increases the risk of fatal injury. The presences of alcohol in medico-legal autopsies are regularly found and this study includes only the victims of violent deaths for which blood alcohol analysis were made. The aim of this study is to certify the occurrence of alcohol consumption in victims of violent deaths in the Federal District. Among the analyzed cases (446), the average blood alcohol content was $1.74 \mathrm{~g} / \mathrm{l}$, being higher in males $(1.76 \pm 1.2 \mathrm{~g} / \mathrm{l})$ than in females $(1.53 \pm 1 \mathrm{~g} / \mathrm{l})$.
The 446 cases analyzed correspond to $30 \%$ of all medicolegal autopsies performed in 2014. In our country, in the years 2008, 2012 and 2013, stricter laws were implemented with more severe punishments to those who drive under the influence of alcohol. These accounted for a significant decrease in the number of deaths caused from traffic accidents. Currently, the leading cause of violent death in our region is homicides by firearms.

There is growing interest in the consequences of alcohol consumption in relation to the health of the population, both with regard to the consequences of long-term abuse, such as chronic diseases, especially liver cirrhosis. Generally, the risk of violent death due to alcohol depends on four factors:

- Frequency with which the person drinks during the period.

- Amount of the alcohol the person drinks on each occasion.

- Context in which the person is drinking.

- How the person behaves under the influence of alcohol.

Violent death has a multiplicity of causes and alcohol poisoning is one [11].

Alcohol intoxication has been considered a major cause of violence and crime. The increase of a federal rate in the US in 1991, which increased the price of alcohol by $6 \%$ reduced the number of deaths by $4.5 \%$ and had an even greater effect on violent crime [3].

Fitterer et al. [12] did a search and identified 87 relevant studies on alcohol access and violence conduct intervention analysis. Seventy-one (82\%) reported a significant relationship between alcohol access and violent offenses. Results from baseline studies indicated the effectiveness of increasing the price of commonly consumed alcohol, restricting the hours of alcohol trading, and limiting the number of alcohol outlets per region to prevent violent offenses.

In a study to correlate the cause of death in the phase of absorption of alcohol, they found that most of the deaths occurred in the postabsorptive phase (86\%), close to the peak. They believe that after small doses of alcohol and low levels of blood alcohol $(<0.5 \mathrm{~g} / \mathrm{l})$, people become more talkative and less inhibited. Drinking large amounts of alcohol to achieve levels above $1.0 \mathrm{mg} / \mathrm{dl}$ leads to confusion and impaired cognitive and psychomotor function. Larger quantities of alcohol, reaching levels above $3.0 \mathrm{~g} / \mathrm{l}$ lead to gross intoxication, stupor and risk of death from respiratory depression and circulatory collapse [13].

In our country, in the city of Rio de Janeiro, the study concluded that there was a positive correlation between episodes of aggression, falls, victims of firearm projectile, hanging, drowning and the values of blood concentration of alcohol, although prevalence of these corresponds to $23 \%$ of all circumstances [14]. In Rio Grande do Sul, in Porto Alegre, survey of 1585 victims of violent death, $53.3 \%$ had blood alcohol content above $6 \mathrm{mg} / \mathrm{dl}$ [15].

Finland (population of 5.1 million) has the highest accident mortality rates, suicides and murders within the European Union. Study by Lunetta [16] shows that $23.3 \%$ of the 45,544 violent deaths that occurred during the period of $87-96$ were related to alcohol consumption. Between the ages of 15-64 years, in $28.6 \%$ of the accidents, $30.5 \%$ of suicides and $55.3 \%$ of murders were associated with alcohol.

In South Africa, alcohol is one of the most significant public health problems and has an important impact on the criminal justice system with strong evidences of the association between high levels of alcohol 
Page 4 of 6

and risk behavior. In a review of 1,455 cases of violent death, where the alcohol was dosed, they found a rate of $47 \%$ of positive cases with concentrations ranging between 0.01 and $0.95 \mathrm{~g} / 100 \mathrm{ml}$. The most affected group was that between 18-29 years, although the average age was 36 years [17]. In this study, traffic accidents and deaths related to firearms were cases where the blood alcohol levels were prevalent.

Bilban [18] and Skibin [19] examined 1,630 cases of violent death, which were necropsied at the institute, between 1995-1999 and found that the presence of alcohol was established in $76.3 \%$ of cases. In cases included in the study, $38.2 \%$ were accidents at work, $28.8 \%$ were homicide victims, $25.4 \%$ were suicides, $24.6 \%$ were involved in traffic accidents and $19.3 \%$ were accidents in homes. $23.2 \%$ of all victims had blood alcohol concentrations above $1.5 \mathrm{~g} / \mathrm{l}$. The highest values were found in cadavers aged between 35 and 44 years. In Slovenia, it is assumed that 173,000 people are alcoholics; the suicide rate coincides with the consumption of alcohol per capita. The alcohol concentration ranged from $0.01 \mathrm{~g} / 1$ to $5.66 \mathrm{~g} / \mathrm{l}$. All levels above 0.20 were considered intoxicants.

Kumar et al. [20] analyzed 200 drivers involved in road accidents presented to trauma emergency. $54.5 \%$ of injured drivers were positive for alcohol and/or drug use. Most commonly abused substance among the drivers involved in road accidents was alcohol (40.5\%). The majority of positive cases belonged to the age group of 25-34 years $(61.5 \%)$ and $60 \%$ of subjects in the age group of 18 -34 years were found to be positive for psychoactive substances in their urine.

Andreucceti [21] analyzed victims of homicide in São Paulo and its association with alcohol. A total of 2,042 victims of homicide data were obtained from cadaveric examination. The victims were predominantly male (93\% of cases), mean age $30.4 \pm 11.5$ years. The prevalence of positive blood alcohol was higher in men $(44.1 \%$ vs. $26.6 \%)$. Regarding the method of death, most were by firearms (78.6\%), followed by white weapons $(9.5 \%)$ and other methods (11.9\%).

In Norway, analysis of 1,539 forensic autopsies showed that concentrations above $0.5 \%$ was found in $47.6 \%$ of the violent deaths and $93 \%$ of the alcohol were above $1.0 \%$. They concluded that alcohol postmortem above $0.5 \%$ should be seen as a possible contributing cause of all violent deaths [22]. A different study was conducted by Combs-Orme et al. [23] considering already diagnosed alcoholics. In a follow-up study of 1,289 alcoholics, 6-9 years after treatment, 52 had died by violent deaths. Suicide and homicide were the main causes, with fire deaths and traffic accidents coming next.

Our study showed that the average blood alcohol concentration checked in the victims of traffic accidents was $2.03 \pm 1.03 \mathrm{~g} / \mathrm{l}$. In a study published in 2008, before the new traffic laws in the same region, the author analyzed 442 deaths from traffic accidents and found that most of the victims were young males, between 18 and 35 years old. Among the victims of collision vehicles, $44.2 \%$ had blood alcohol levels above $0.6 \mathrm{~g} / \mathrm{l}$; of victims of overturns, this percentage was $57.7 \%$ and among pedestrians, 32.5\% [24]. Another study conducted in DF-IML in 2010 showed that alcohol was detected in $47.4 \%$ of samples, with over $30 \%$ showing blood concentration alcohol levels higher than $1 \mathrm{~g} / \mathrm{l}$ [25].

The decrease of tolerated blood alcohol levels has been one of the ways to reduce the mortality rate in traffic accidents. The District of Columbia and 29 more states have limited lower values for less than 21 years, which resulted in a decrease of $16 \%$ of the number of fatal accidents $[26,27]$.
After World War II, the number of vehicles has increased rapidly in Japan. This increase was accompanied by an increase in the number of traffic accidents. In 1970 and 1978, Japan introduced laws establishing limits for maximum alcohol concentration to $0.25 \mathrm{mg} / \mathrm{l}$ and stricter laws. Due to high rates of death from traffic accidents in 2002, the Japanese government lowered the limit to $0.15 \mathrm{mg} / \mathrm{l}$ and the number of deaths from traffic accidents dropped significantly [28].

In New Zealand, one case-control study was conducted with 571 drivers involved in traffic accidents. It is estimated that if blood alcohol concentration is above $100 \mathrm{mg} / \mathrm{mL}$, the risk of accidents increases 13-18 times and risk of fatal accidents 50-90 times. Other parameters may also influence the results of traffic accidents: use of seatbelts, road conditions, chronic alcohol use, number of fatalities, etc. [29]. About a quarter of all deaths from traffic accidents are associated with alcohol. In addition, to favor the occurrence of traffic accidents, alcohol impairs their survival in non-fatal cases. The vasodilation caused by alcohol can interfere with the shock responsive vasoconstriction. The cough reflex depression can exacerbate airway obstruction caused by vomiting so common in alcoholics and victims of fatal injuries.

The diagnosis and treatment of head injuries are greatly impaired by alcohol that depresses the levels of consciousness. Hypotension can also be due to resulting dehydration of the diuretic effect of alcohol during the absorptive phase. Alcohol also causes changes in the metabolic response to trauma, low glucose and alanine and high lactate and ketone bodies in plasma. Liver damage can complicate anesthesia, decrease platelet aggregation and prolonging bleeding time, decreased the resistance and chronic anemia [30].

Traffic accidents have multicausality

- Basic determinants like population compounds, social organization and environment.

- Structural determinants like the country's motorization rate, level of urbanization, road signs, traffic law, social tolerance for alcohol and other drugs, the percentage of drivers under 25 and over 65 years.

- Other determinants like vehicular congestion on public roads, poor condition of the road or signage, bad weather conditions, speeding, clumsiness in handling the vehicle and ethanol intoxication of the driver. The human factor (especially alcohol) is the factor with the greatest weight in multicausality [31].

Alcohol is also a major risk factor in cases of drowning. A review of 36 studies published in English between 1950 to 1985 found that blood alcohol levels ranged from $29-86 \%$ depending on the immersion time. They concluded that $25-50 \%$ of adult drowning victims had consumed alcohol [32]. In California, in 1974-1985, 41\% of drowning deaths were associated with alcohol consumption. In cases of alcohol above 200 $\mathrm{mg} / \mathrm{dl}$, the possibility of involvement of alcohol is greater [33]. Drowning is the third most frequent cause of unnatural deaths in the world. Drowning mortality rates are higher in developing countries. Globally, deaths from drowning are more common among children and male.

In Sweden, deaths from drowning still represent a significant proportion of the cases of deaths from external causes (6\%), which may occur during several activities in the water. Study in a period of 18 years, conducted with 5,125 cases, with an incidence of 3.1/100,000, it showed that the prevalence was higher in men with a mean age of 53 years. Out of this total, alcohol was carried out in 4,377 (91\% of cases) and $38 \%$ had values above $0.2 \mathrm{~g} / \mathrm{l}$, with an average of $1.8 \mathrm{~g} / \mathrm{l}(0.2$ to 5.2$)$ [34]. All our cases were considered accidental. In the series above, they 
Page 5 of 6

identified 21 cases of murder and $31 \%$ of cases were considered suicide. In cases of suicide, $24 \%$ had positive blood alcohol levels. A substantial proportion (44\%) of deaths from drowning, unintentional, had blood alcohol concentration positive. These results can be compared with $51 \%$ in Finland [35], 35-55\% in the US [36], 50\% in New Zealand [37], 62\% in Ireland [38], and 22\% in Australia [39]. We analyzed 39 cases of suicide ( $9 \%$ of total), and found that the highest levels of alcohol was with those victims of firearms $(2.96 \mathrm{~g} / \mathrm{l})$. In the case of hangings, the average alcohol was $1.41 \mathrm{~g} / \mathrm{l}$ and victims of height falls, $1.28 \mathrm{~g} / \mathrm{l}$. The average age of suicide was $41.26 \pm 11.18$ years with male predominance $(87 \%)$.

Croft et al. [40] found that alcohol was involved in a high proportion of accidental immersion drowning (61\%) and was highest for males aged 20-24 years. There is a strong global trend showing that males are at higher risk of drowning than females.

Suicide is a major public health problem in the USA and worldwide. With approximately 37,000 deaths annually, suicide was in 10th place among the causes of death in the US in 2009. The suicide rate for men and women was 19.2 and 5.0 per 100,000 individuals. Analysis of 57,813 victims in 16 states showed that $24 \%$ of men and $17 \%$ of women were intoxicated at the time of death [41]. Alcohol and drugs are only secondary to depression and other mood changes as the most important risk factors for suicide. Opiates and antidepressants are strongly associated with suicide, while amphetamines, cocaine and marijuana are associated with homicide. Amphetamine users are more likely to adopt a more aggressive behavior [42]. Sweden has a population of 9.2 million and about 1,000 suicides occur annually. In a review of 10 years, the authors found that about $34 \%$ of victims of suicide had consumed alcohol before death $(36 \%$ of men and $31 \%$ of women). The mean age was $51.3 \pm 18.8$ years, with a clear predominance of males (71\%). The average concentration for men was $1.34 \mathrm{~g} / \mathrm{l}$ for women and was $1.25 \mathrm{~g} / \mathrm{l}$, and the highest levels were found in alcohol poisoning and death by asphyxia gas. Alcohol consumption leads to loss of inhibition, impulsive behavior, impaired judgment and a tendency to take risks, all of which can increase the propensity of individuals to suicide. Some studies have called attention to predisposing factors such as psychiatric illness, impulsivity and aggressive behavior, but little attention was given to alcohol or its role. In Sweden, about $20-25 \%$ of all deaths were due to suicide [43].

Kaplan et al. [44] found that the fraction of all suicide decedents with alcohol intoxication increased by $7 \%$ after the onset of the recession. Compared to the years prior to the recession, male suicide decedents showed a 1.09-fold increased risk of alcohol intoxication within the first two years of the recession. Their findings suggest that acute alcohol intoxication in suicide interacts with economic conditions, becoming more prevalent during contractions.

Several studies have established a strong connection between acute intoxication, alcoholism and suicide, as the last act of alcoholism or an act of desperation in a family of alcoholics, an act of escape from depression or as a means of self-destruction. In Slovenia, 600 people a year commit suicide. In a review, they found that alcohol was the contributing factor to suicide in at least $38.1 \%$ of suicide, aged 33-54 years, who are recurrent consumers or alcoholics. The most vulnerable groups were workers with basic school level, widowed, divorced, unemployed, alcoholics and farmers. There was a male predominance and hanging was the preferred method of suicide (58.3\%). Women often use the drowning and falling heights as mechanisms. The average concentration of alcohol was $0.57 \mathrm{~g} / \mathrm{l}$, being higher in suicides by traffic accidents, $1.81 \mathrm{~g} / 1$ [18].
Zerbini et al. [45] analyzed in Sao Paulo, 184 cases of hanging in 2007 and found that the victims were predominantly male $(84.2 \%)$ with mean age of 38.2. For females, the average age was 37.3 years. Blood alcohol concentration was found in $37.5 \%$ of the victims. The average blood alcohol was $1.8 \mathrm{~g} / \mathrm{l} \pm 0.9 \mathrm{~g} / \mathrm{l}$.

\section{Conclusion}

External causes are becoming a significant burden to people throughout the world and reducing its morbidity and mortality is one of the main challenges for public health. Knowing the influence of alcohol in each region is the first step towards the introduction of more stringent measures and counseling of the population. Our study confirms the findings in the literature, showing huge contribution of alcohol factor in violent deaths. Stricter laws and public awareness campaigns should be instituted to reduce the mortality related to alcohol. In our region, homicides and traffic accidents are the leading causes of violent deaths.

\section{References:}

1. Dubowski KM (1985) Absorption, distribution and elimination of alcohol: Highway safety aspects. J Stud Alcohol 10:98-108.

2. França GV (2015) Medicina Legal. 10th Edn. Guanabara Koogan, Portuguese

3. Cook PJ, Durrance CP (2013) The virtuous tax: lifesaving and crime prevention effects of the 1991 federal alcohol-tax increase. J Health Econ 32: 261-266.

4. Charness ME, Simon RP, Greenberg DA (1989) Ethanol and the nervous system. N Engl J Med 321: 442-454.

5. (1907) Alcohol and Traffic Accidents. The Lancet 169: 1030-1031.

6. Glucksman E (1994) Alcohol and accidents. Brit med J 50: 76-84.

7. Gururaj G (2004) Alcohol and road traffic injuries in South Asia: Challenges for prevention. J Coll Physicians Surg Pak 14: 713-718.

8. Cox DE, Sadler DW, Pounder DJ (1997) Alcohol estimation at necropsy: Epidemiology, economics, and the elderly. J Clin Pathol 50: 197-201.

9. Gawryszewski VP, Koizumi MS, Mello-Jorge MHP (2004) External causes in Brazil in 2000 : Comparing mortality and morbidity. Cad Public Health 20: 995-1003.

10. Reza A, Mercy JA, Krug E (2001) Epidemiology of violent deaths in the world. Inj Prev 7: 104-111.

11. Skog OJ (1986) Trends in alcohol consumption and violent deaths. Brit J Addict 81: 365-379.

12. Fitterer JL, Nelson TA, Stockwell T (2015) A Review of the Existing Studies Reporting the negative effects of alcohol access and positive effects of alcohol control policies on interpersonal violence. Front Public Health 3: 253.

13. Lathi RA, Pitkaniemi J, Jones AW, Sajantila A, Poikolainen K, et al. (2014) Cause and manner of death and phase of the blood alcohol curve. Forensic Sci Int 244: 306-312.

14. Cruz CC, Sarcinelli PN, Silva JJO, Meyer TSM, Bochner R, et al. (2014) External causes related to alcohol recorded by the Forensic Institute in the city of Rio de Janeiro. Cad. Saúde Colet 22: 8-15.

15. Gomes LCD, Stein AT, Bigolin AV, Lenzi LGS, Vitor RS (2010) Prevalence of alcoholemy in deaths from traffic accidents and other external causes. Revista da AMRIGS 54: 273-277.

16. Lunetta P, Pentilla A, Sarna S (2001) The role of alcohol in Accident and violent deaths in Finland. Alcohol Clin Exp Res 25: 1654-1661.

17. Ehmke U, Toit-Prinsloo LD, Saayman G (2014) A retrospective analysis of alcohol in medico-legal autopsied deaths in Pretoria over a 1 year period. Forensic Sci Int 245C: 7-11.

18. Bilban M, Skibin L (2005) Presence of alcohol in suicide victims. Forensic Sci Int 147: S9-S12. 
Page 6 of 6

19. Skibin L, Bilban M, Balazic J (2005) Harmful alcohol use of those who died a violent death (the extended region of Ljubljana 1995-1999). Forensic Sci Int 147: S49-S52.

20. Kumar S, Bansal YS, Singh D, Medhi B (2015) Alcohol and Drug use in injured drivers - An emergency room study in a Regional Tertiary Care Centre of North West India. J Clin Diagn Res 9: HC01-HC04.

21. Andreuccetti G, de Carvalho HB, de Carvalho PJ, de Carvalho DG, Kahn T, et al. (2009) Alcohol consumption in homicide victims in the city of São Paulo. Addiction 104: 1998-2006.

22. Nordrum I, Eide TJ, Jorgensen L (2000) Alcohol in a series of medicolegally autopsied deaths in northern Norway 1973-1992. Forensic Sci Int 110: 127-137.

23. Combs-orme T, Taylor JR, Scott EB, Holmes SJ (1983) Violent deaths among alcoholics. A descriptive study. J Stud Alcohol 44: 938-949.

24. Modelli MES, Pratesi R, Tauil PL (2008) Blood alcohol concentration in fatal traffic accidents in the Federal District, Brazil. Rev Public Health 42 : $1-3$.

25. Campelo ELC, Caldas ED (2010) Postmortem data related to drug and toxic substance use in the Federal District, Brazil, from 2006 to 2008 Forensic Sci Int 200: 136-140.

26. Hingson R, Heeren T, Winter M (1994) Lower legal blood alcohol limits for young drivers. Public Health Rep 109: 738-744.

27. Hingson R, Heeren T, Winter M (1996) Lowering state legal blood alcohol limits to 0,08\%: The effect on fatal motor vehicle crashes. Am J Public Health 86: 1297-1299.

28. Masahito H, Sorimachi Y, Kurosu A, Nagai T, Tokudome S (2003) The risk of death due to alcohol-impaired driving in Japan. The lancet 361: 1132 .

29. Connor J, Norton R, Ameratunga S, Jackson R (2004) The contribution of alcohol to serious car crash injuries. Epidemiology 15: 337-344.

30. Raffle PAB (1989) Interrelation between alcohol and accidents. J R Soc Med 82: 132-135.

31. Pedrouzo RAV (2004) Causes of traffic accidents from a vision of socia medicine . El combination alcoho - transit. Rev Med Urug 20: 178-186.

32. Howland J, Hingson R (1988) Alcohol as a risk factor for drownings: A review of the literature (1950-1985). Accid Anal Prev 20: 19-25.

33. Wintemute GJ, Teret SP, Kraus JF, Wright M (1990) Alcohol and drowning: An analysis of contributing factors and a discussion of criteria for case selection. Accid Anal Prev 22: 291-296.
34. Ahlm K, Saveman B, Bjornstig U (2013) Drowning deaths in Sweden with emphasis on the presence of alcohol and drugs - a retrospective study, 1992-2009. BMC Public Health 13: 216.

35. Lunetta P, Smith GS, Penttila A, Sajantila A (2004) Unintentional drowning in Finland 1970-2000: a population-based study. Int J Epidemiol 33: 1053-1063.

36. Browne ML, Lewis-Michl EL, Stark AD (2003) Watercraft-related drownings among New York State residents, 1988-1994. Public Health Rep 118: 459-463.

37. Warner M, Smith GS, Langley JD (2000) Drowning and alcohol in New Zealand: what do the coroner's files tell us? Aust N Z J Public Health 24: 387-390.

38. Ingoldsby H, Callagy G (2010) Alcohol and unnatural deaths in the West of Ireland: a 5-year review. J Clin Pathol 63: 900-903.

39. Franklin RC, Scarr JP, Pearn JH (2010) Reducing drowning deaths: the continued challenge of immersion fatalities in Australia. Med J Aust 192: 123-126.

40. Croft JL, Button C (2015) Interacting factors associated with adult male drowning in New Zealand. PloS One10: e0130545.

41. Kaplan MS, McFarland BH, Huguet N, Conner $\mathrm{K}$, Caetano R, et al. (2013) Acute alcohol intoxication and suicide: a gender-stratified analysis of the National Violent Death Reporting System. Inj Prev 19: 38-43.

42. Sheehan CM, Rogers RG, Williams GW, Boardman JD (2012) Gender differences in the presence of drugs in violent deaths. Addiction 108: 547-555.

43. Holmgren A, Jones AW (2010) Demographics of suicide victims in Sweden in relation to their blood-alcohol concentration and the circumstances and manner of death. Forensic Sci Int 198: 17-22.

44. Kaplan MS, Huguet N, Caetano R, Giesbrecht N, Kerr WC, et al. (2015) Economic Contraction, Alcohol intoxication and suicide: Analysis of the National Violent Death Reporting System. Inj Prev 21: 35-41.

45. Zerbini T, Ponce JC, Sinagawa DM, Cintra RB, Munoz DR, et al. (2012) Blood alcohol levels in suicide by hanging cases in the state of São Paulo, Brazil. J Forensic Leg Med 19: 294-296. 